\title{
Green HACCP: Food Safety and Environment
}

\author{
Mohamed Zarid \\ Department of Agricultural \& Food Engineering, Regional Campus of International Excellence “Campus Mare Nostrum” (CMN), \\ Universidad Politecnica de Cartagena (UPCT), Paseo Alfonso XIII, 48, ETSIA, E-30203 Cartagena, Murcia, Spain
}

\begin{abstract}
Green HACCP (hazard analysis and critical control point) is a new control method developed by combining food safety controls and good practices for environmental protection, in order to have a safe production that respects the environment. Indeed, some of production practices, such as the use of large amount of water, cleaning/disinfection products and other practices used to have safe foodstuffs, could affect the environment and the profitability in several agri-food process. The goal of Green HACCP is to apply a sustainable rationalization of the good hygienic and environmental practices.
\end{abstract}

Key words: Quality, food safety, environment, parallel control system, agri-food industries.

\section{Introduction}

HACCP is a method of food safety control developed in the United States by a NASA-based laboratory, with the assistance of Pillsbury since 1959, the objective of which is the prevention, elimination or reduction to an acceptable level of all biological, chemical and physical hazards [1]. To do this, the approach consists of a hazard analysis allowing the establishment of critical points where it is possible to control them. Developed by experts through international collaboration over the years, HACCP is a good example of a standard that has been adopted by states and regulatory authorities. In fact, this tool has become a standard or more precisely a standard concept and is now imposed by various regulations of the European authorities for food hygiene including the regulation 178/2002 [2]. The HACCP system was then introduced in the European Union in 1993 by Directive 93/43/EC on the hygiene of foodstuffs [3].

Green HACCP is a new method that combines between the classic method of food safety control (HACCP) and ERP (environmental respect practices).

Corresponding author: Mohamed Zarid, researcher, research fields: advanced techniques in research and development of food engineering and agriculture.
It is based firstly on awareness and responsibility towards the environment. Green HCCP uses a governance approach in manufacturing and control to ensure a safe product and to protect or to minimize the impact on the environment, with a flexibility to choose the efficient ways to achieve this goal.

Among the practices which could be important for the environment protection in some agri-food manufacturing process, it is important for example to:

- Optimize the use of products affecting the environment as in the case of cleaning and disinfection products, etc.

- Optimize the use of water in the manufacturing process or for raw materials and/or equipment cleaning.

- Computerize documentation if possible, instead of using paper.

- Recycling everything that could be recyclable and could be reused.

Also, the Green HACCP can be oriented to the optimization and/or waste treatment, wastewater treatment and why not to develop a "Green and safe Process" that can ensure a general respect for the environment and facilitate an environmental management system implementation (ISO 14001 standard). 


\section{Principles of Green HACCP System}

Green HACCP, as the classical HACCP system, is based on the following principles (Fig. 1): identify, evaluate and describe control measures, through a conscience respect and also a parallel control system of the environment.

Principle 1: Conduct a hazard analysis.

Principle 2: Determine CCP (critical control points).

Principle 3: Set the critical threshold(s).

Principle 4: Establish a monitoring system for hazard control measures at CCPs.

Principle 5: Determine corrective actions to be taken if necessary.

Principle 6: Apply verification procedures to confirm that the Green HACCP system is working effectively.

Principle 7: Create a file containing all the procedures and statements concerning these principles and their implementation (traceability).

It is possible to add a principle which requests the environmental awareness and respect by control methods and sensibilization. That is to say that all company's departments especially quality management, maintenance and production should be engaged to apply the Green HACCP principles and communicate retrospectively the "Green controls" results.

The Green HACCP method not only allows for some vigilance in identifying steps where there is a contamination hazard, but also takes environmental respect in producing as a priority.

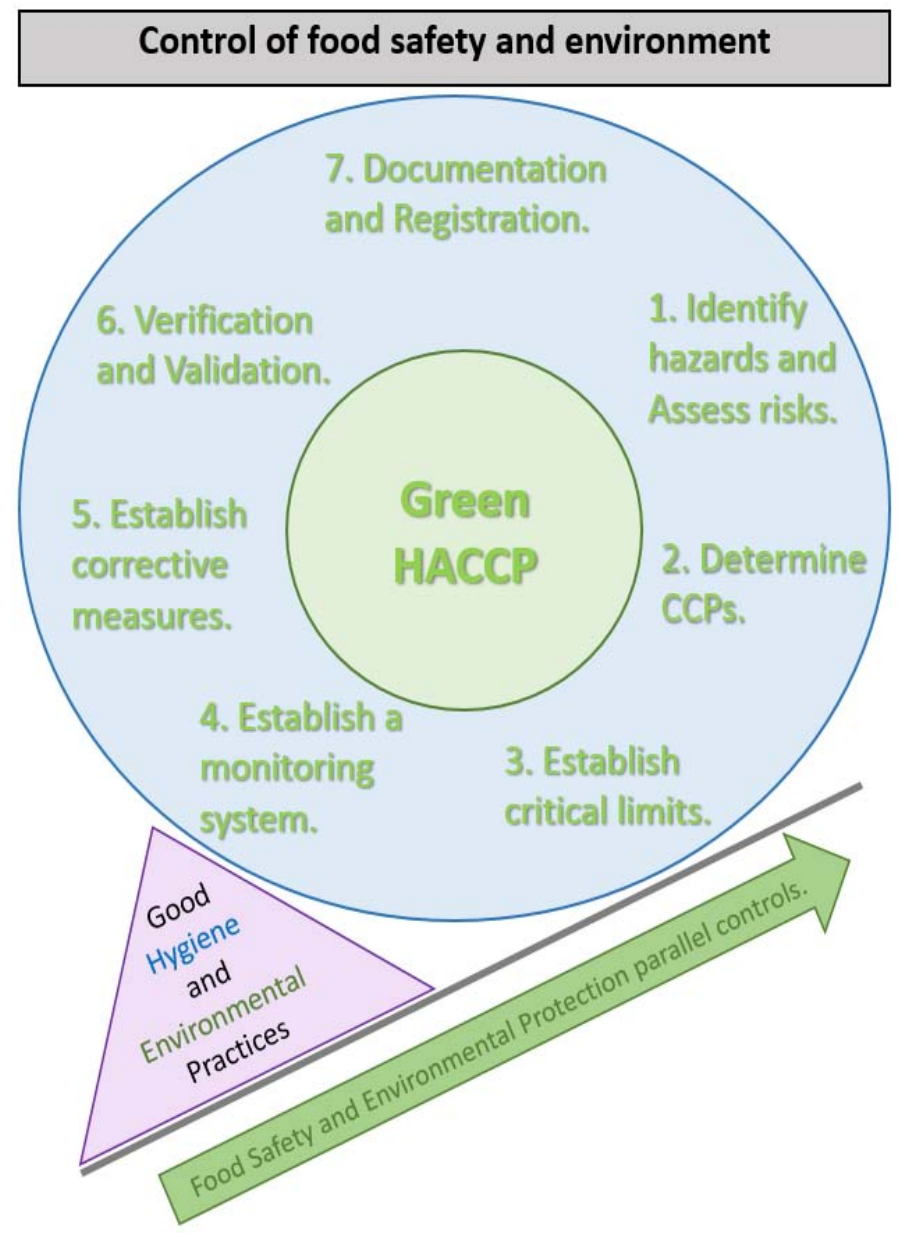

Fig. 1 Green HACCP approach. 


\section{Prerequisites for Implementation}

Since 2005, the ISO 22000 standard proposes a food safety management system that complies with all the current legislative requirements related to food safety (the Hygiene Package), combining the well-known approach of the standards with quality management (ISO 9000: 2000) with Codex Alimentarius standards on GHP and HACCP. Moreover, Green HACCP proposes the integration of the environment component to have a more complete system [4].

The establishment of Green HACCP requires preparation. The management should first commit and set goals to achieve on the one hand. On the other hand, it has to readapt its food safety and environment protection policy and involve all the company's staff. Besides, Green HACCP team must be multidisciplinary and competent to develop a Green HACCP plan to consider all aspects of manufacturing and benefit from feedback [5].

Before proceeding with the Green HACCP analysis, it is necessary to set up a plan of good hygiene practices (BPH) and ERP. This plan should relate the food sector concerned in accordance with the regulations according to the Hygiene Package and using the "Guides of good practice of hygiene and application of the principles HACCP” taking into consideration the protection of the environment. That is why it is necessary to properly master the BPH and ERP before going further in the process. In fact, GHP and ERP are the roots of Green HACCP.

\section{Setting-up}

Production diagram must be made considering the recycling stages, the inputs and outputs of materials, the different fluids, the packaging and the existing control measures for the BPH and ERP. The manufacturing diagram must be checked on the production site in consultation with the production team (manager, team leaders, operators). Hazard analysis consists of: (1) identifying the hazards (physical, chemical and microbiological) during the different stages of the production process; (2) evaluating the frequency of occurrence and the severity of these hazards (potential or significant); (3) putting in place control measures (Principle 1), with environmental awareness [6].

\section{Risk to Confusion}

Just as the classical method, Green HACCP is not an elimination of all hazards, a zero-risk application or a precautionary principle. It is about the control of hazards identified by the prevention relying on CCP and respecting the environment. It is therefore not a question of hygiene everywhere and for everything but of relying on critical points where control measures are applied focusing on an environmental awareness. In fact, Green HACCP must be the main concern of production. Many companies usually have good documentation which was not applied in the field. This observation leaves us to wonder where the environment respect in manufacturing process is. Indeed, in the field, we observe practices, habits and customs of production, and often we note that the current production practices are not quite in agreement with the pre-established procedures. GHP and ERP are the prerequisites for Green HACCP.

\section{Implications for the Future}

To better understand the Green HACCP approach, beyond safe products to discover its environmental advantages and economic beneficiaries, its application in different agri-food process is necessary.

\section{Conclusions}

Green HACCP is an awareness and responsibility towards the environment before being a control method. Once adopted, it could be beneficial for agri-food industries to optimize some costs and may allow being engaged in the environment protection. 


\section{References}

[1] From HACCP to ISO 22000. 2008. Management of Food Safety. Olivier Boutou-AFNOR.

[2] ISO 22000 Certification. 2010. The 8 Keys to Success. Olivier Boutou-AFNOR.

[3] ISO 22000, HACCP and food safety-Recommendations, tools, FAQs and field feedback Didier Blanc, AFNOR 2009 (1st edition 2005)—Recommendations, tools, FAQs and feedback from the field summarizes good practices in food safety, specifies the requirements of ISO 22000 and illustrates these principles with concrete examples.
[4] Champiat, D., Matas, N., Monfort, B., and Fraass, H. 2001. "Applications of BioChemiLuminescence to HACCP.” Luminescence 16: 193-8.

[5] Valat, C., Champiat, D., Degorcedumas, J., and Thomas, O. 2003. "Using Bioluminescence Biosensors for Hazard Analysis and Critical Control Point (HACCP) in Wastewater Control.” Water Science and Technology 49 (1): 131-8.

[6] "How to Use the ISO 22000-Handbook for SMEs: Published in 2013 by ISO. http://www.iso.org/iso/en/home/store/publications_a nd_e-products/publication_item.htm?pid=PUB100340. 